\title{
Assessment of Convective Activity Using Stability Indices as Inferred from Radiosonde and MODIS Data
}

\author{
P. R. Jayakrishnan, C. A. Babu \\ Department of Atmospheric Sciences, Cochin University of Science and Technology, Cochin, India \\ Email: prjayakrishnan@gmail.com
}

Received November 28, 2013; revised December 25, 2013; accepted January 2, 2014

Copyright (C) 2014 P. R. Jayakrishnan, C. A. Babu. This is an open access article distributed under the Creative Commons Attribution License, which permits unrestricted use, distribution, and reproduction in any medium, provided the original work is properly cited. In accordance of the Creative Commons Attribution License all Copyrights (C) 2014 are reserved for SCIRP and the owner of the intellectual property P. R. Jayakrishnan, C. A. Babu. All Copyright @ 2014 are guarded by law and by SCIRP as a guardian.

\section{ABSTRACT}

The combined use of both radiosonde data and three-dimensional satellite derived data over ocean and land is useful for a better understanding of atmospheric thermodynamics. Here, an attempt is made to study the thermodynamic structure of convective atmosphere during pre-monsoon season over southwest peninsular India utilizing satellite derived data and radiosonde data. The stability indices were computed for the selected stations over southwest peninsular India viz: Thiruvananthapuram and Cochin, using the radiosonde data for five premonsoon seasons. The stability indices studied for the region are Showalter Index (SI), K Index (KI), Lifted Index (LI), Total Totals Index (TTI), Humidity Index (HI), Deep Convective Index (DCI) and thermodynamic parameters such as Convective Available Potential Energy (CAPE) and Convective Inhibition Energy (CINE). The traditional Showalter Index has been modified to incorporate the thermodynamics over tropical region. MODIS data over South Peninsular India are also used for the study. When there is a convective system over south peninsular India, the value of LI over the region is less than $\mathbf{- 4}$. On the other hand, the region where LI is more than 2 is comparatively stable without any convection. Similarly, when KI values are in the range 35 to 40 , there is a possibility for convection. The threshold value for TTI is found to be between 50 and 55 . Further, we found that prior to convection, dry bulb temperature at $1000,850,700$ and $500 \mathrm{hPa}$ is minimum and the dew point temperature is a maximum, which leads to increase in relative humidity. The total column water vapor is maximum in the convective region and minimum in the stable region. The threshold values for the different stability indices are found to agree with that reported in literature.

\section{KEYWORDS}

Atmospheric Thermodynamics; Stability Indices; Convection

\section{Introduction}

Convective activity in the atmosphere is driven by the instability prevailing over the atmosphere. Many methods were employed for assessing the convective activity of the atmosphere. Many researchers have extensively attempted forecasts of thunderstorms using stability indices and classified their skill scores (Huntrieser et al. [1]; Schultz [2]; Fuelberg et al. [3]; Jacovides and Yonetani [4]; Peppier [5]). It is important to validate different thunderstorm indices over different regions for a better forecast. A simple stability index was developed by Showalter [6], based on the thermodynamic principles to give a quick assessment on the thunderstorm possibility. Since then many other stability indices were developed for the prediction of convective activity over the mid latitude region. They are Lifted index (Galway [7]), K Index (George [8]), SWEAT (Miller [9]), and CAPE (Moncrieff and Green [10], Kunz [11]) studied about the skill of convective parameters and indices to predict the convective activity over the South West Germany. He could obtain better results with the use of SI, LI and KI. Convective indices are used to obtain a quick check of thunderstorm possibility. They were found to have threshold values of which is the possibility for the formation of convective activity and hence occurrence of thunderstorm. They are derived from the daily radiosonde data. 
These indices are useful in the prediction of severe weather events.

Over the Indian region, especially over northeast India, several studies on thunderstorm forecasting were conducted in the past (Rao and Raman [12]; Tyagi [13]; Koteswaram and Srinivasan [14]). Synoptic features associated with pre-monsoon thunderstorms over Assam were studied by Sen and Basu [15]. A study by Choudhary [16] revealed that the low level convergence and orographic lifting are principal causes for thunderstorm development in northeastern region of India. Mukhopadhyay et al. [17] studied the pre-monsoon thunderstorm activities using conventional thunderstorm indices over three northeast Indian stations. Karmakar and Alam [18] analyzed the potential of different stability indices and their spatial distribution over Dhaka. They studied the indices using a frequency table and range of values for each index.

Over the Indian region, several studies were carried out about the relation of thunderstorm indices with thermodynamic parameters on convective activity (Kumar, [19]; Asoilal [20]; Lal [21]; Tyagi et al. [22]; Litta and Mohanty [23]). The convective activity prevailing over the atmosphere is the feeding mechanism for the development of weather systems such as thunderstorms and cyclones. The variations in marine atmospheric boundary layer as well as the heat budget components associated with the formation of a super cyclone Gonu in the Arabian Sea have been studied extensively by Jayakrishnan and Babu $[24,25]$. In this study, we made an attempt to understand the role of stability indices and thermodynamic parameters for identifying convective activity of the atmosphere over southwest peninsular India during pre-monsoon season utilizing radiosonde data and three-dimensional satellite derived data.

\section{Data and Methodology}

The thermodynamic structure of the atmosphere was studied in detail for the southwest peninsular India during pre-monsoon season (March to May) for five years (2003-2007) employing stability indices and thermodynamic parameters. We made analysis for the two stations viz: Thiruvananthapuram (TVM: $8^{\circ} 48^{\prime} \mathrm{N}, 79^{\circ} 5^{\prime} \mathrm{E}$ ) and Cochin $\left(9^{\circ} 5^{\prime} \mathrm{N}, 76^{\circ} 27^{\prime} \mathrm{E}\right)$, utilizing radiosonde data. The stability indices used for the study include Showalter Index (SI), K Index (KI), Lifted Index (LI), Total Totals Index (TTI), Humidity Index (HI) and Deep Convective Index (DCI). Tuduri and Ramis [26] suggested that stability indices need not be effective outside the geographical locations for which it was originally developed. To improve the performance of Showalter Index further, it was modified for the region by incorporating Lifting
Condensation Level (LCL) as the saturation level rather than simply approximating the saturation level as 850 $\mathrm{hPa}$ and named as modified Showalter Index. Here, the modification of SI was done by lifting air parcel from $950 \mathrm{hPa}$ to LCL dry adiabatically and then saturated adiabatically from LCL to $500 \mathrm{hPa}$. We made the modification considering that the air parcel gets saturated first at LCL, which is generally at a lower level below 850 $\mathrm{hPa}$ in the tropics. High CAPE values above $1000 \mathrm{~J} \cdot \mathrm{kg}^{-1}$ and CINE values less than $-100 \mathrm{~J} \cdot \mathrm{kg}^{-1}$ were considered as the indicators for convective activity. We took radiosonde observation at 12 UTC because the thermodynamic structure in the afternoon (local time 17:30 IST) reflects convective activity. METEOSAT cloud imageries are used to identify the cloud pattern associated with meso scale convective system.

\section{MODIS Data Description}

While the MODIS is not a sounding instrument, it does have many of the spectral bands found on the High resolution Infrared Radiation Sounder (HIRS). Thus it is possible to generate profiles of temperature and moisture as well as total column estimates of precipitable water vapor, ozone, and atmospheric stability from the MODIS infrared radiance measurements. The MODIS Atmospheric Profile product consists of several parameters: they are total-ozone burden, atmospheric stability, temperature and moisture profiles, and atmospheric water vapor. All of these parameters are produced day and night for Level 2 at $5 \times 51-\mathrm{km}$ pixel resolution when at least 9 FOVs are cloud free. There are two MODIS Atmosphere Profile data product files: MOD07_L2, containing data collected from the Terra platform; and MYD07_L2, containing data collected from the Aqua platform. There are different levels of processed data which range from L0 through L4. L0 data is raw instrument data at full resolution and is used as input for L1 processing. For our study we used the Terra level-2 data (http://ladsweb.nascom.nasa.gov/).

The data is in HDF format. We processed the HDF data using HDF processing softwares available and converted the data into ASCII. Then the different parameters were computed using the available data.

MODIS sensor on board EOS satellite series gives atmospheric profiles of temperature, humidity and water vapor content with high spatial resolution. It also gives different stability indices such as Lifted Index, K Index, Total Totals Index, temperature at 1000, 950, 850, 700 and $500 \mathrm{hPa}$ levels and dew point temperature in these levels. MODIS data was downloaded from the archives of MODIS for pre-monsoon season in which thunderstorm occurred over the station.

The thermodynamic parameters, CAPE (Convective 
Available Potential Energy), CINE (Convection Inhibition Energy) and different stability indices were evaluated from the radiosonde data (procured from the RAOB site: (http://www.esrl.noaa.gov/raobs/) as per the detailed methodology described in Babu [27] based on the following equations

$$
\begin{aligned}
& C A P E=-\int_{P L F C}^{P L N B}\left(T_{v p}-T_{v e}\right) R_{d} d(\ln P) \\
& C I N E=-\int_{P S \text { urface }}^{P L F C}\left(T_{v p}-T_{v e}\right) R_{d} d(\ln P)
\end{aligned}
$$

where $P_{L F C}$ is the level of free convection for the air parcel raised from the surface, $P_{L N B}$ is the level of neutral buoyancy for the parcel, $T_{v e}$ is the virtual temperature of the environment at pressure level $P$ through which parcel rises, $T_{v p}$ is the virtual temperature of the parcel and $R_{d}$ is ideal gas constant for dry air.

Many studies were reported on stability indices for the prediction of thunderstorms (Anthes [28]; Neumann [29] described application of different stability indices for forecasting of convective clouds. During convective situations, advection of warm air in the lower levels and cold air in the upper levels increase the conditional instability favoring the development of severe weather events (Rao [30]; Rao et al. [31]. SI (Showalter [6], LI (Galway [7]), KI (George [8]), TTI (Miller [9]), HI (Litynska et al. [32]), and DCI (Barlow [33]) values were computed using the following equations.

$$
\text { Showalter Stability Index: } S I=T_{500}-T_{p 500}
$$

where $T_{500}$ is the dry bulb temperature at $500 \mathrm{hPa}$ and $T_{p 500}$ is the parcel temperature at $500 \mathrm{hPa}$ in which the parcel is being lifted from $950 \mathrm{hPa}$ to LCL dry adiabatically and then saturated adiabatically from LCL to 500 $\mathrm{hPa}$

Surface based Lifted Index: $L I=T_{500}-T_{p 500}$

Where $T_{500}$ is the dry bulb temperature at $500 \mathrm{hPa}$ and $T_{p 500}$ is the parcel temperature in which the parcel is being lifted from surface to LCL dry adiabatically and then saturated adiabatically to $500 \mathrm{hPa}$.

$$
\begin{gathered}
K I=\left(T_{850}-T_{500}\right)+T_{d 850}-\left(T_{700}-T_{d 700}\right) \\
T T I=T_{850}-T_{d 850}-2 *\left(T_{500}\right) \\
H I=\left(T-T_{d}\right)_{850}+\left(T-T_{d}\right)_{700}+\left(T-T_{d}\right)_{500} \\
D C I=\left(T+T_{d}\right)_{850}-L I
\end{gathered}
$$

where $T$ is the temperature and $T_{d}$ is the dew point temperature at corresponding levels.

\section{Results and Discussions}

\subsection{Analysis of Stability Indices Derived Using Radiosonde Data during Pre-Monsoon Season}

\subsubsection{Modified Showalter Index}

Figure 1(a) gives the different ranges of Modified SI and their frequency of occurence for convective activity over Cochin and Thiruvananthapuram. The different ranges are from -9 to 12 with an interval of 3 . We found that maximum probability of $90 \%$ is in the range of 0 to -3 , followed by $84 \%$ in the range of 3 to 0 and $82 \%$ in the range of -3 to -6 for Cochin. For Thiruvananthapuram also more frequencies are towards the lower range of Modified Showalter Index and the maximum probability is $88 \%$ in the frequency range of -6 to -9 . In the study by Karmakar and Alam [18], they obtained maximum frequency range for SI when the value of SI is between -3 to 3 . There is a sharp increase in the probability for convection when the Showalter Index values decrease, which shows the suitability of modified Showalter Index as an appropriate predictor for convective activity in the region.

\subsubsection{Lifted Index}

In the literature, although no specific LI thresholds were developed, the value -2 was used as an upper bound for convection by Miller $([34,35])$ while David and Smith [36] found values $<0$ for LI during convective activity. Figure 1(b) shows the ranges of LI values and their frequency distribution for Cochin and Thiruvananthapuram for the pre-monsoon periods. Maximum percentage of occurrence of convection for LI is noticed when the value of LI is below -3. For Cochin, maximum probability of $92 \%$ and $83 \%$ are obtained, when LI values are in the range -3 to -6 and -6 to -9 respectively. In the case of LI also there is a linear dependency on decreasing LI and increasing convection, which confirms the suitability of LI for the prediction of convection over tropics. For Thiruvananthapuram, the maximum probability for convection of $90 \%$ and $86 \%$ were obtained when LI values are in the range 0 to -3 and -3 to -6 respectively.

\subsubsection{Total Totals Index}

The threshold value of TTI was found to be +44 by Miller [34,35]. Figure 1(c) gives the ranges and percentage of convection of Total Totals Index. TTI values range from 30 to 60 with an interval of 5 . More percentage of convection was obtained for Cochin when TTI values are in the range 50 - 55. For Thiruvananthapuram, more probability of convection was obtained when TTI values are in the range $40-45$. TTI values do not show linear dependency on the convective activity as evident from the figure. So TTI alone is not a good predictor when 

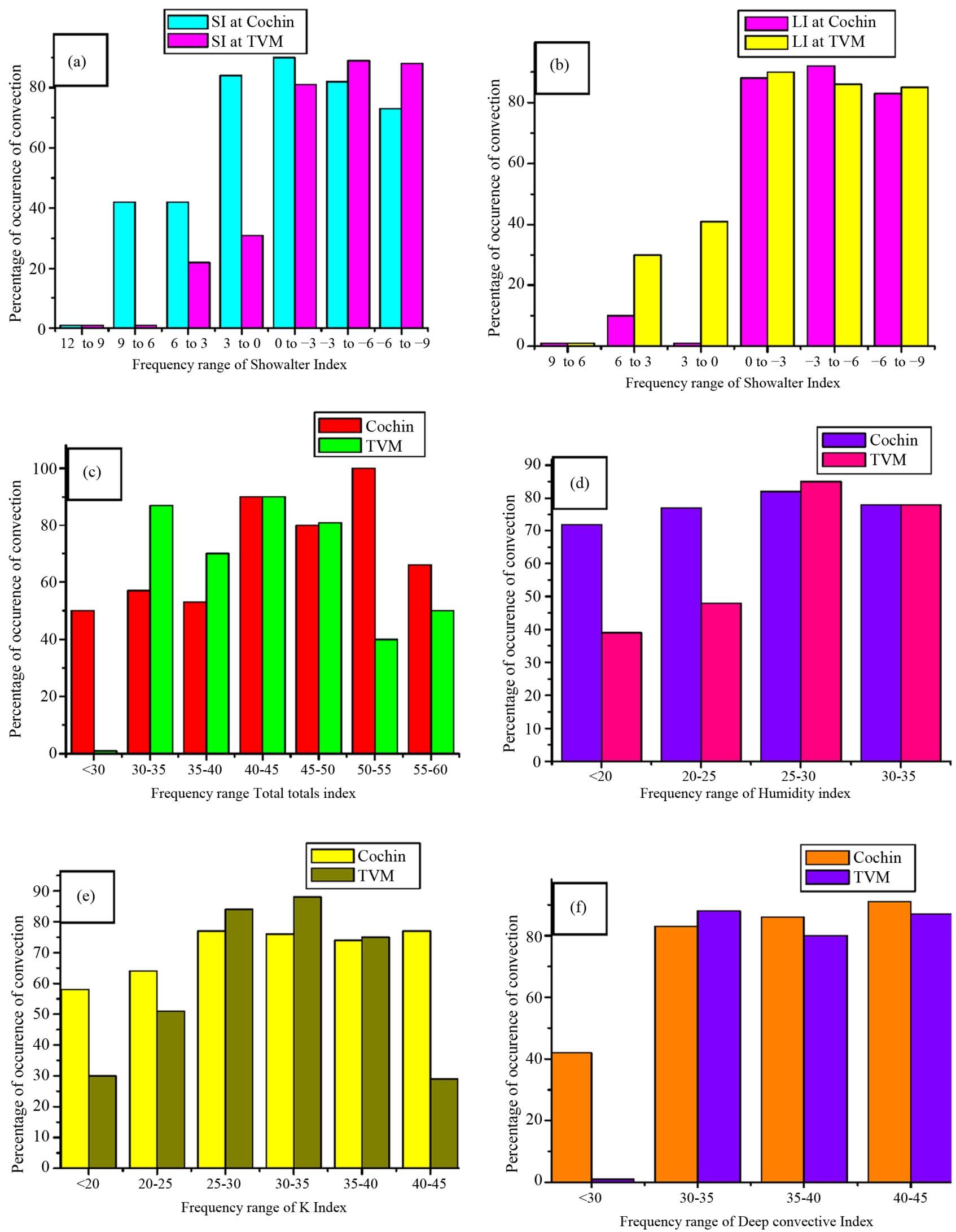

Figure 1. Percentage of occurrence of convection of the different stability indices: (a) Showalter index; (b) Lifted Index; (c) Total totals index; (d) Humidity Index; (e) K Index; (f) Deep Convective index. 
considered individually over the study region.

\subsubsection{Humidity Index}

The normal values of HI range from 20 to 35. Figure 1(d) represents the percentage of convection with HI values. More probability of $82 \%$ and $78 \%$ were obtained when the HI values are in the range 25 - 30 and 30 - 35 respectively, for Cochin. For Thiruvananthapuram, maximum probability of $85 \%$ is obtained when $\mathrm{HI}$ is in the range 25 - 30. This shows that HI is a comparatively good predictor for convection.

\subsubsection{K Index}

Figure 1(e) depicts the percentage of occurrence of convection of KI. The values are divided into different ranges starting from 20 and ending in 60. For these KI values, the frequency of occurrence of convection has been calculated. Over Cochin, maximum probability of $77 \%, 76 \%$ and $74 \%$ were obtained when KI values are in the range 25 - 30, 30 - 35, and 35 - 40 respectively. For Thiruvananthapuram, maximum percentage of occurrence were obtained as $84 \%, 88 \%$ and $75 \%$ in the frequency range, 25 - 30, 30 - 35 and 35 - 40.

\subsubsection{Deep Convective Index}

The frequency percentage of DCI values are shown in Figure 1(f). DCI values are given with a frequency starting from 30 and ending in 50 with an interval of 5. It is found that for Cochin, the maximum probability of $86 \%$ and $91 \%$ were noticed when the DCI values are in the range 35 - 40 and 40 - 45. But for Thiruvananthapuram, maximum percentage of $88 \%$ is obtained when DCI values are in the range 30 - 35. It is evident that if DCI values are above 35 , there is a possibility of convective activity.

\subsection{Analysis of Thermodynamic Structure of Atmosphere during Occurrence of a Thunderstorm on 29th April 2010 Using MODIS Data}

\section{Synoptic Situation on 29th April 2010}

On $29^{\text {th }}$ April 2010, a thunderstorm activity was reported at 5.30 PM IST over Cochin. The pre-convective structure of the atmosphere is captured by MODIS satellite. Figure 2 shows the METEOSAT cloud images over south Indian region on $29^{\text {th }}$ April 2010. The figure represents cloud observations during 00 UTC, 06 UTC, 12 UTC and 18 UTC. The cloudiness associated with the thunderstorm activity is evident from the satellite image at 12 UTC. Different stability indices and three-dimensional structure of the atmosphere are studied here.

Analysis of stability indices SI, LI, KI, TTI, DCI, HI and thermodynamic parameters LCL, LFC, CAPE CINE Figure 3 gives the spatial distribution of different stabil-

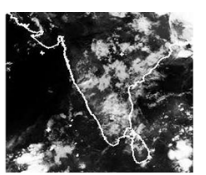

29 April 2010 0000 UTC

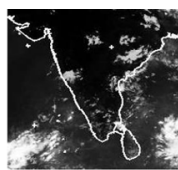

29 April 2010 0600 UTC

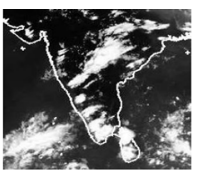

29 April 2010 1200 UTC

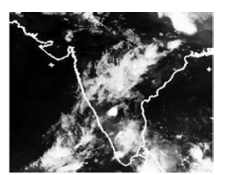

29 April 2010 1800 UTC
Figure 2. Meteosat images on 29 April 2010.

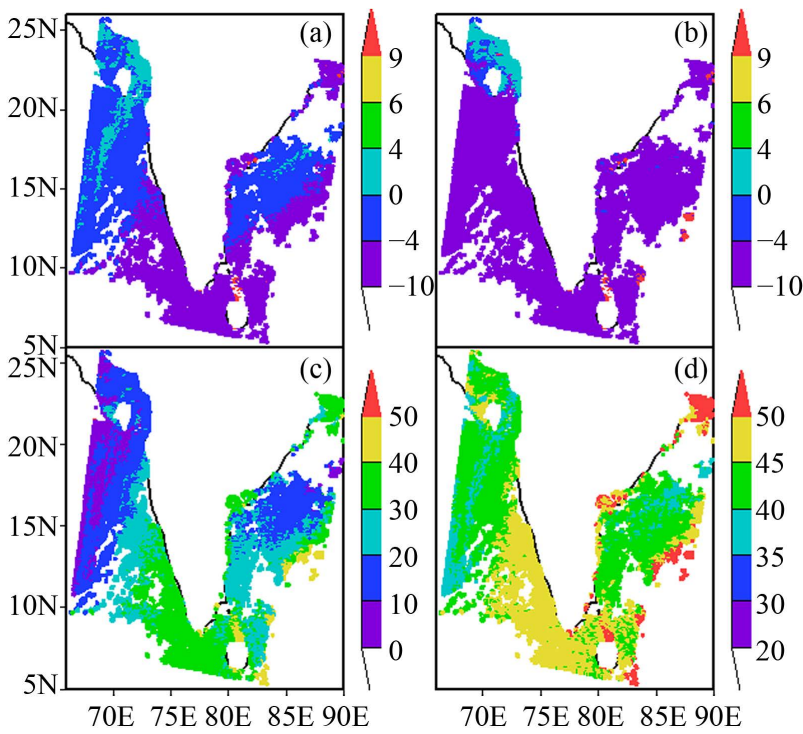

Figure 3. Spatial distribution of thermodynamic indices on 29 April 2010 (a) SI; (b) LI; (c) KI; (d) TTI.

ity indices over South Indian peninsula on $29^{\text {th }}$ April 2010 at 10.55 IST. From IMD reports, a mesoscale convective system was formed over the region on the evening of $29^{\text {th }}$ April. We have examined three-dimensional spatial distribution of thermodynamic parameters and indices over the region at the time of occurrence of convective system.

In the region of formation of thunderstorm, Showalter Index value was between -1 to -5 which shows high unstable nature of the atmosphere which is favorable for convection (Figure 3(a)). The LI also shows favorable condition for unstable atmosphere with value between -2 to -7 (Figure 3(b)). The value of $\mathrm{KI}$ is in between 28 32 , which also agrees with the convective nature of the atmosphere (Figure 3(c)). The TTI has value in between 44 - 48, which also show the conducive state for convective activity (Figure 3(d)). In the region of formation of thunderstorm, the LCL and LFC values (Figures 4(a) and (b)) come to low pressure levels with values 952 and $900 \mathrm{hPa}$ respectively. Due to the high convective nature of the system, the CAPE values were between 3000 to $4000 \mathrm{~J} \cdot \mathrm{kg}^{-1}$ (Figure 4(c)) and CINE values were below $-700 \mathrm{~J} \cdot \mathrm{kg}^{-1}$ (Figure 4(d)) that also favours convection. Over the convective region DCI have value between 35 to 40 and $\mathrm{HI}$ is having value between 12 to 18 (Figures 5 (a) and (b)). 


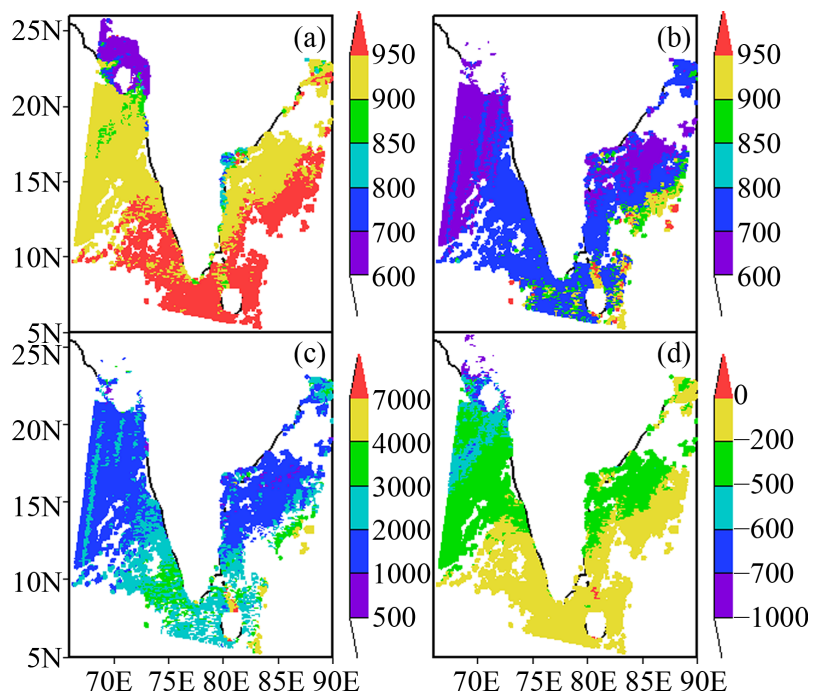

Figure 4. Spatial distribution of thermodynamic parameters on 29 April 2010 (a) LCL; (b) LFC; (c) CAPE; (d) CINE.

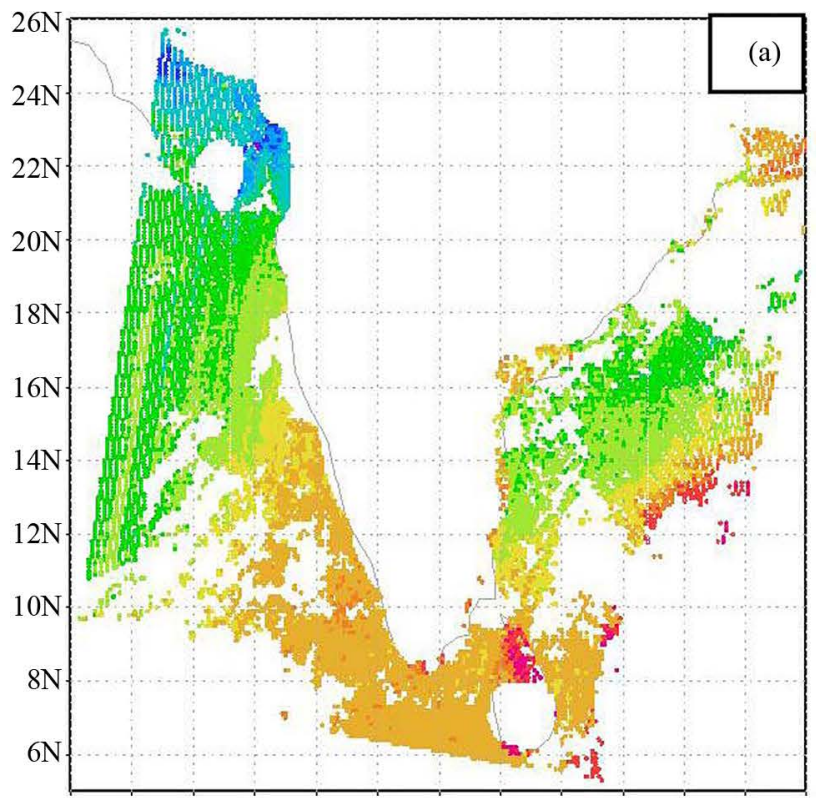

$66 \mathrm{E} \quad 68 \mathrm{E} 70 \mathrm{E} 72 \mathrm{E} 74 \mathrm{E} 76 \mathrm{E} \quad 78 \mathrm{E} \quad 80 \mathrm{E} \quad 82 \mathrm{E} \quad 84 \mathrm{E} \quad 86 \mathrm{E} \quad 88 \mathrm{E} 90 \mathrm{E}$

$10.8144 \quad 1821.625 .228 .832 .4 \quad 38 \quad 39.643 .246 .850 .4$

\subsection{Comparison between MODIS and Radiosonde Data}

Tables 1-7 give the comparison of stability indices and thermodynamic parameters derived using MODIS data and radiosonde (RAOB: RAwinsonde OBservation) data during the pre-monsoon season of March-May, 2006. The parameters are computed for Cochin station for different days. From the table it is evident that almost all the parameters are in good agreement with the MODIS data in comparison with the radiosonde data. So MODIS atomspheric profile product could be used in the regions where radiosonde data is absent. Figure 6(a) gives the comparison of dry bulb temperature profile using MODIS and radiosonde data. From the figure it is obvious that the temperature values using radiosonde and MODIS data are in good agreement. Also Figure 6(b) depicts the comparison between dew point temperature derived using both radiosonde and MODIS data. Dew point tem-

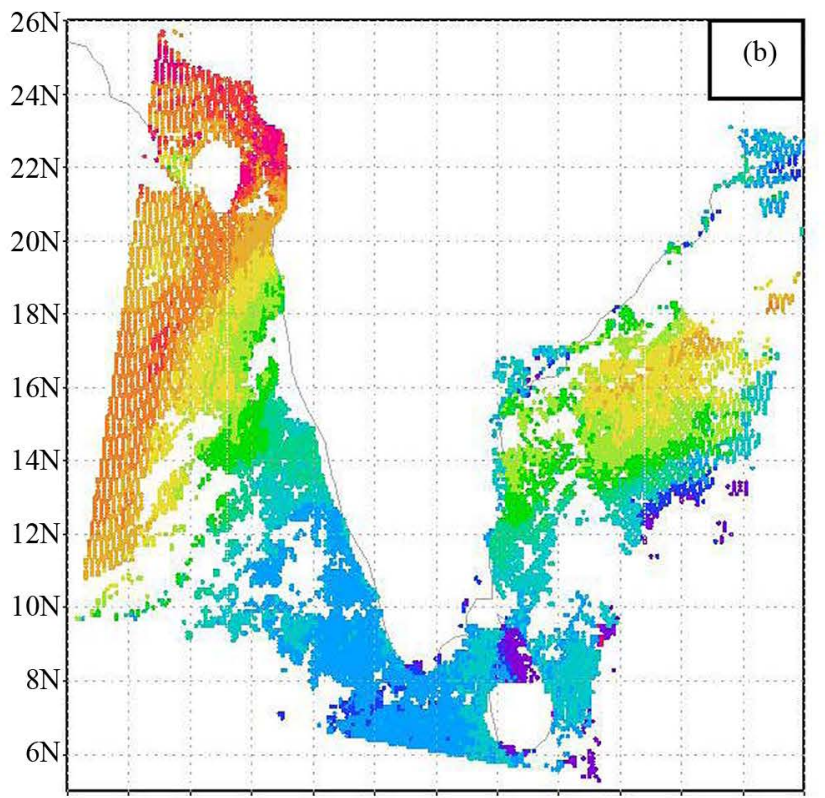

$66 \mathrm{E} \quad 68 \mathrm{E} \quad 70 \mathrm{E} \quad 72 \mathrm{E} \quad 74 \mathrm{E} \quad 76 \mathrm{E} \quad 78 \mathrm{E} \quad 80 \mathrm{E} \quad 82 \mathrm{E} \quad 84 \mathrm{E} \quad 86 \mathrm{E} 88 \mathrm{E} \quad 90 \mathrm{E}$

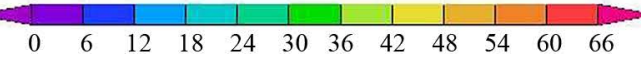

Figure 5. Spatial distribution of thermodynamic indices on 29 April 2010 (a) DCI; (b) HI.

Table 1. Comparison on MODIS and RAOB profiles on $1^{\text {st }}$ March 2006, 17:55 UTC.

\begin{tabular}{ccccccccccc}
\hline DATA & LCL & LFC & CAPE & CINE & KI & TTI & HI & DCI & LI & SI \\
\hline MODIS & 959 & 730 & 1457 & -52 & 35 & 47 & 17.8 & 40 & -4.9 & -3.9 \\
RAOB & 837.2 & 896.0 & 2478.7 & -12.1 & 25 & 33.3 & 15 & 29.9 & -5.2 & -2.69 \\
12 UTC & & & & & & & & & &
\end{tabular}

Table 2. Comparison on MODIS and RAOB profiles on $7^{\text {st }}$ March 2006, 05:30 UTC.

\begin{tabular}{ccccccccccc}
\hline DATA & LCL & LFC & CAPE & CINE & KI & TTI & HI & DCI & LI & SI \\
\hline MODIS & 997 & 722 & 1533 & -191 & 34 & 48 & 21.5 & 39 & -6.2 & -3.6 \\
RAOB & 944.8 & 620.0 & 1169.5 & -432.8 & 31.0 & 48.6 & 58.1 & 39.7 & -2.18 & -4.6 \\
00 UTC & & & & & & & & & &
\end{tabular}


Table 3. Comparison on MODIS and RAOB profiles on $11^{\text {th }}$ March 2006, 06:00 UTC.

\begin{tabular}{|c|c|c|c|c|c|c|c|c|c|c|}
\hline DATA & LCL & LFC & CAPE & CINE & $\mathrm{KI}$ & TTI & HI & DCI & LI & SI \\
\hline MODIS & 959 & 888 & 2233 & -31 & 34 & 50 & 25.6 & 43 & -6.5 & -6.6 \\
\hline $\begin{array}{l}\text { RAOB } \\
00 \text { UTC }\end{array}$ & 980.0 & 950 & 2427 & -58 & 34.1 & 49.8 & 26.0 & 38.1 & -7.7 & -7.7 \\
\hline
\end{tabular}

Table 4. Comparison on MODIS and RAOB profiles on $2^{\text {nd }}$ April 2006, 05:25 UTC.

\begin{tabular}{ccccccccccc}
\hline DATA & LCL & LFC & CAPE & CINE & KI & TTI & HI & DCI & LI & SI \\
\hline MODIS & 939 & 686 & 1656 & -263 & 16 & 40 & 55 & 30 & -2.7 & -1.1 \\
RAOB & 946.9 & 886.0 & 1124.4 & -39.6 & 35.3 & 438 & 30 & 38.6 & -4.2 & -5.8 \\
00 UTC & & & & & & & & & \\
\hline
\end{tabular}

Table 5. Comparison on MODIS and RAOB profiles on $3^{\text {rd }}$ April 2006, 17:00 UTC.

\begin{tabular}{ccccccccccc}
\hline DATA & LCL & LFC & CAPE & CINE & KI & TTI & HI & DCI & LI & SI \\
\hline MODIS & 952 & 686 & 630 & -214 & 23 & 42 & 44.2 & 32 & -2.8 & -0.4 \\
RAOB & 969.3 & 969.3 & 877.4 & 3.1 & 29.4 & 42.0 & 44.7 & 36.1 & -7.12 & -7.12 \\
00 UTC & & & & &
\end{tabular}

Table 6. Comparison on MODIS and RAOB profiles on $4^{\text {th }}$ April 2006, 17:40 UTC.

\begin{tabular}{ccccccccccc}
\hline DATA & LCL & LFC & CAPE & CINE & KI & TTI & HI & DCI & LI & SI \\
\hline MODIS & 957 & 694 & 829 & -204 & 27 & 44 & 36.2 & 36 & -3.7 & -1.2 \\
RAOB & 881.2 & 814.0 & 501.6 & -45.2 & 32.1 & 44.6 & 52.0 & 41.3 & -5.7 & -1.55 \\
00 UTC & 881.2 & & & & & & & & &
\end{tabular}

Table 7. Comparison on MODIS and RAOB profiles on $21^{\text {st }}$ May 2006, 17:00 UTC.

\begin{tabular}{ccccccccccc}
\hline DATA & LCL & LFC & CAPE & CINE & KI & TTI & HI & DCI & LI & SI \\
\hline MODIS & 960 & 726 & 1226 & -114 & 42 & 50 & 45 & 39 & -4.3 & -3.5 \\
RAOB & 822.6 & 740 & 1193 & -130 & 28 & 43 & 28 & 38 & -2.8 & 1.14 \\
00 UTC & & & & & & & & & & \\
\hline
\end{tabular}

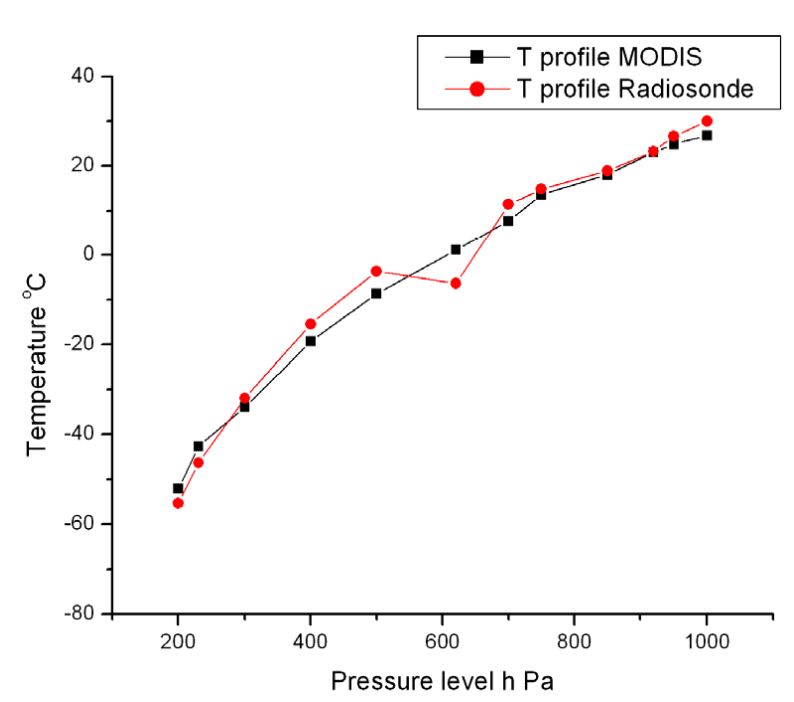

(a)

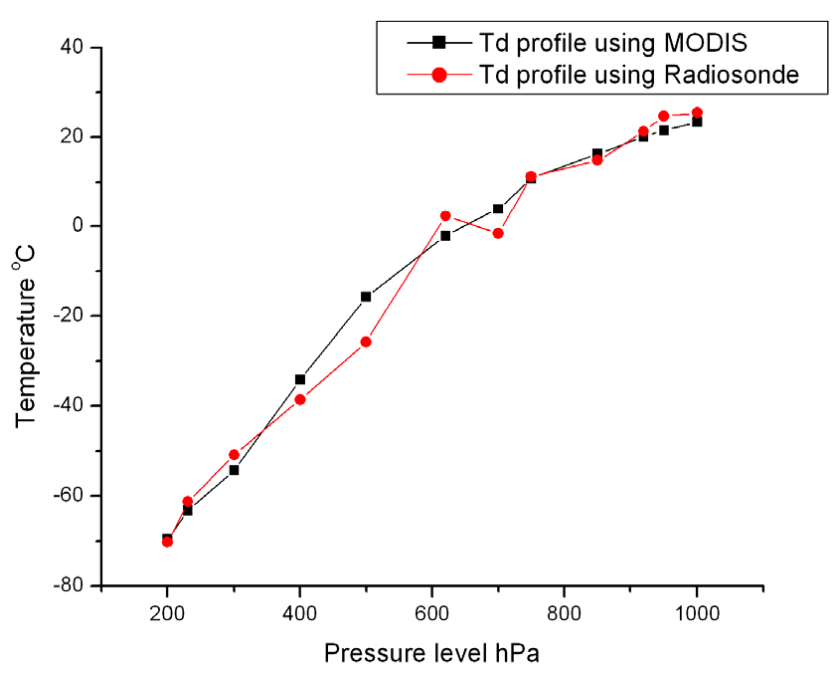

(b)

Figure 6. Comparison of (a) T profile and (b) Td profile using radiosonde data and MODIS data.

perature profiles obtained from MODIS and radiosonde shows good agreement. The Root Mean Square error was found out using the equation

$$
\text { RMS Error }=\sqrt{\frac{\sum_{i=1}^{n}(T r-T m)^{2}}{n}}
$$


Where $\operatorname{Tr}$ is the temperature derived from radiosonde data and $T m$ is the temperature from MODIS data. For the dew point temperature the R.M.S. error was 4.11 and for the dry bulb temperature the R.M.S error estimate was 3.57 as can be viewed from Figure 6. Also we have found out the RMS error for the T and Td at different heights and found that RMS error is varying at different heights between the observed value and satellite derived one.

\section{Conclusion}

The radio sonde data can be used over the land region and utilized for the assessment of convection. But when there is a lack of data over the oceanic region, the MODIS atmospheric profile product data could replace the radiosonde data. Here comes the potential use of satellite derived data in assessing the convection and forecasting weather activity. A comparison between radiosonde data and MODIS data has been done and found that it is closely matching. The convective activity of the atmosphere over southwest peninsular India responds to the values of thermodynamic indices and parameters during pre-monsoon. The skill scores of different stability indices during convective activity are brought out. The Showalter index is modified by incorporating LCL value at the saturation level since the saturation level is below $850 \mathrm{hPa}$ and the modified Showalter Index yields encouraging results for assessing convective activity over southwest Peninsular Indian region. The possibility of convection using different stability indices and thermodynamic profiles was studied using MODIS data. Threedimensional thermodynamic structure is obtained through MODIS satellite derived products. The LI has very low negative values in the range -4 to -5 over unstable regions. The values of KI are in the range 40 - 45 over the unstable region. The TTI values are in the range 50 - 55 over the unstable regions and very low values over the stable regions.

\section{Acknowledgements}

The first author acknowledges the fellowship received from CSIR, New Delhi during the period of the work. We acknowledge MODIS web site for providing data.

\section{REFERENCES}

[1] H. Huntrieser, H. H. Schiesser, W. Schmid and A. Waldvogel, "Comparison of Traditional and Newly Developed Thunderstorm Indices for Switzerland," Weather Forecasting, Vol. 12, No. 1, 1997, pp. 108-125. http://dx.doi.org/10.1175/1520-0434(1997)012<0108:CO $\underline{\text { TAND }>2.0 . C O ; 2}$

[2] P. Schultz, "Relationships of Several Stability Indices to
Convective Weather Events in Northeast Colorado," Weather Forecasting, Vol. 4, No. 1, 1989, pp. 73-80. http://dx.doi.org/10.1175/1520-0434(1989)004<0073:RO $\underline{\text { SSIT }>2.0 . C O ; 2}$

[3] H. E. Fuelberg and D. G. Biggar, "The Pre-Convective Environment of Summer Thunderstorms over the Flororida Panhandle," Wether Forecasting, Vol. 9, No. 3, 1994, pp. 316-326.

http://dx.doi.org/10.1175/1520-0434(1994)009<0316:TP EOST>2.0.CO;2

[4] C. P. Jacovides and T. Yonctani, “An Evaluation of Stability Indices for Thunderstorm Prediction in Greater Cyprus,” Wether Forcasting, Vol. 5, No. 4, 1990, pp. 559-569. http://dx.doi.org/10.1175/1520-0434(1990)005<0559:AE $\underline{\mathrm{OSIF}>2.0 . \mathrm{CO} ; 2}$

[5] R. A. Peppier, "A Review of Static Stability Indices and Related Thermodynamic Parameters,” SWS Miscellaneous Publication, 1988, p. 104

[6] A. K. Showalter, "A Stability Index for Thunderstorm Forecasting," Bulletin of the American Meteorological Society, Vol. 34, No. 6, 1953, pp. 250- 252.

[7] J. G. Galway, "The Lifted Index as a Predictor of Latent Instability,” Bulletin of the American Meteorological Society, Vol. 37, 1956, pp. 528-529.

[8] J. G. George, "Weather Forecasting for Aeronautics," Academic Press, 1960, p. 673.

[9] R. C. Miller, "Notes on Analysis and Severe Storm Forecasting Procedures of the Air Force Global Weather Central,” Tech. Report 200 (Revised), AWS, 1972, USAF. [Headquarters, AWS, Scott AFB, IL 62225].

[10] M. W. Moncrieff and J. S. A. Green, "The Propagation of Steady Convective Overturning in Shear," Quarternary Journal of Roal Meteorological Society, Vol. 98, 1972, pp. 336-352.

[11] M. Kunz, "The Skill of Convective Parameters and Indices to Predict Isolated and Severe Thunderstorms," Natural Hazards and Earth System Sciences, Vol. 7, 2007, pp. 327-342. http://dx.doi.org/10.5194/nhess-7-327-2007

[12] K. N. Rao and P. K. Raman, "Frequency of Days of Thunder in India," Indian Journal of Meteorology and Geophysics, Vol. 1, 1961, pp. 103-108.

[13] A. Tyagi, "Thunderstorm Climatology over Indian Region,” Mausam, Vol. 58, No. 2, 2007, pp. 189-212.

[14] P. Koteswaram and V. Srinivasan, "Thunderstorms over Gangetic West Bengal in the Pre-Monsoon Season and the Synoptic Factors Favorable for Their Formation," Indian Journal of Meteorology and Geophysics, Vol. 10, 1958, pp. 301-312.

[15] S. N. Sen and S. C. Basu, "Pre-Monsoon Thunderstorm in Assam and Synoptic Conditions Favourable for Their Occurrence,” Mausam, Vol. 12, No. 1, 1961, pp. 15-20.

[16] A. K. Choudhury, "Pre-Monsoon Thunderstorm in Assam, Tripura and Manipur," Indian Journal of Meteorology and Geophysics, Vol. 12, 1961, pp. 319-321.

[17] P. Mukhopadhyay, J. Sanjay and S. S. Singh, “Objective Forecast of Thundery/Non-Thundery Days Using Conventional Indices over Three Northeast Indian Stations," Mausam, Vol. 16, No. 4, 2003, pp. 867-880. 
[18] S. Karmakar and M. Alam, "Instability of the Troposphere Associated with Thunderstorms/Nor'westers over Bangladesh during the Pre-Monsoon Season,” Mausam, Vol. 57, No. 4, 2006, pp. 629-628.

[19] S. Kumar, "An Objective Method of Forecasting Premonsoon Thunderstorm/Duststorm over Delhi and Neighborhood,” Indian Journal of Meteorology and Geophysics, Vol. 23, 1972, pp. 45-50.

[20] A. Lal, "Forecasting of Thunderstorm around Delhi and Jodhpur,” Mausam, Vol. 40, 1989, pp. 267-268.

[21] R. Lal, "Forecasting of Severe Convective Activity over Lucknow in Premonsoon Season,” Mausam, Vol. 41, 1990, pp. 455-458.

[22] B. Tyagi, V. Naresh Krishna and A. N. V. Satyanarayana, "Study of Thermodynamic Indices in Forecasting PreMonsoon Thunderstorms over Kolkata during STORM Pilot Phase 2006-2008,” Natural Hazards, Vol. 56, No. 3, 2011, pp. 681-698, http://dx.doi.org/10.1007/s11069-010-9582-x

[23] A. J. Litta and U. C. Mohanty, "Simulation of a Severe Thunderstorm Event during the Field Experiment of STORM Programme 2006 Using WRF-NMM Model,” Current Science, Vol. 95, No. 2, 2008, pp. 204-215.

[24] P. R. Jayakrishnan and C. A. Babu, "Variations of Surface Boundary Layer Parameters Associated with Cyclone Gonu over the Arabian Sea Using QuikSCAT Data," International Journal of Remote Sensing, Vol. 34, No. 7, 2013, pp. 2417-2431.

[25] P. R. Jayakrishnan and C. A. Babu, "Study of the Oceanic Heat Budget Components over the Arabian Sea during the Formation and Evolution of Super Cyclone, Gonu," Atmospheric and Climate Sciences, Vol. 3, No. 3, 2013, pp. 282-290.

[26] E. Tudurí and C. Ramis, "On the Environments of Severe Weather in the Western Mediterranean," Weather Forecasting, 1997, p. 11.

[27] C. A. Babu, "Evaluation of Thermodynamic Parameters of the Atmosphere by a Fortran Program," Computers \&
Geosciences, Vol. 22, No. 8, 1996, pp. 877-881. http://dx.doi.org/10.1016/S0098-3004(96)00044-1

[28] R. A. Anthes, "Numerical Prediction of Severe StormsCertainty, Possibility, or Dream," Bulletin of the American Meteorological Society, Vol. 57, 1976, pp. 423-435.

[29] C. J. Neumann, "The Thunderstorm Forecasting System at the Kennedy Space Center," Journal of Applied Meteorology, Vol. 10, No. 5, 1971, pp. 921-936. http://dx.doi.org/10.1175/1520-0450(1971)010<0921:TT FSAT>2.0.CO;2

[30] K. P. R. Rao, "Thunderstorm Studies in India-A Review," Indian Journal of Meteorology and Geophysics, Vol. 12, 1966, p. 3.

[31] K. N. Rao, C. E. J. Daniel and L. V. Balasubramanian, “Thunderstorms over India," IMD Pre-published Scientific Report No. 153, 1971.

[32] Z. Litynska, J. Parfiniewicz and H. Pinkowski, "The Prediction of Airmass Thunderstorms and Hails," W.M.O. Bull, Vol. 450, 1976, pp. 128-130.

[33] W. R. Barlow, "A New Index for the Prediction of Deep Convection, Preprints,” 17th Conference on Severe Local Storms, St. Louis, Amer. Meteor. Soc, 1993, pp. 129-132.

[34] R. C. Miller, "Notes on Analysis and Severe Storm Forecasting Procedures of the Military Weather Warning Center," AWS Tech. Rep. 200, USAF, 1967, 170 pp. [Available from Headquarters, AWS, Scott AFB, IL 62225].

[35] R. C. Miller, "Notes on Analysis and Severe Storm Forecasting Procedures of the Air Force Global Weather Central,” Tech. Report 200 (Revised to include CHANGE 1), AWS, 1975, USAF [Headquarters, AWS, Scott AFB, IL 62225].

[36] C. L. David and J. S. Smith, “An Evaluation of Seven Stability Indices as Predictors of Severe Thunderstorms and Tornadoes," Seventh Conference Severe Local Storms, Kansas City, American Meteorological Society, 1971, pp. 105-109. 